\title{
Standard for design of modern electric distribution system analysis
}

\author{
Li Dongxue $^{1, a}$, Yang Jiye ${ }^{1, a}$, Yan Chuang ${ }^{1, a}$, Ma Qiang ${ }^{1, a}$, Yu Dayong ${ }^{1, a}$, Lu Tianqi ${ }^{1, a}$ \\ ${ }^{1}$ State Grid Liaoning Electric Power CO,LTD. Power Electric Research Institute, Shenyang 110015, \\ China \\ a ldxztg79@163.com
}

Keywords: Power distribution; network design; standards system; Adaptive

Abstract: With the emerging power system files, new energy development and widespread application of new technologies, new materials, new equipment, distribution network design are facing profound change. Paper around new situation Xia power system development mode, to achieved distributed power, and electric, diversified load access for target, main from can Institute, and early set, and construction figure design stage and variable electric, and line, and civil design professional, on both at home and abroad existing of distribution network design standard for Combs, in-depth analysis existing standard in the design stage and professional aspects exists of problem, building new of distribution network planning design standard system, full play standard on distribution grid design work of guide role.

\section{Introduction}

Distribution network is an important part of the grid, facing users directly, is the guarantee of power "was used, the key link", is an important infrastructure of.2015 to improve the livelihood of the year in August, the National Energy Bureau issued a <distribution network construction and transformation plan of action (2015-2020) >, clear and speeding up the construction of distribution network transformation intelligent distribution network, accelerate the upgrade, enhance the adaptability, improve the core competitiveness of the distribution network. In the process of promoting the construction and renovation, playing a leading role in network design a unified strong smart distribution network in the construction of power distribution, action plan clearly put forward a sound distribution network technology standard System requirements. However, the design standard of distribution network planning work in China for a long time lag, has been the lack of scientific and normative standard system. With the country and gradually attach great importance to the construction of distribution network planning, distribution network has released a number of areas for the planning and design standards. In gradually improve the standard and standard in use the problem has also become more and more prominent. Part of the standard and poor timeliness, unable to meet the new requirements of the design of distribution network planning under the new situation. At the same time, the standardization work focuses on standards, the lack of effective management mechanism and standard implementation effect evaluation method, it is difficult to trace, feedback and solve the main problems in the application of this standard. This paper mainly combined with the new technology, relates to the distribution network of our country in the construction of new materials, the development trend of new equipment, the current domestic 
research on the standard system of adaptability, analysis of existing distribution network at different stages of design standard system problems and puts forward some improvement suggestions ${ }^{[1-2]}$.

\section{Characteristics of existing distribution network standard system}

At present, our country adopts the four level system, divided into national standards, industry standards, local standards and enterprise standards four levels. In addition, the standard system can also be divided into compulsory standards and recommended standards. Two kinds of standard system design of distribution network in China is relatively mature, the characteristics of the national grid company based design with the construction of distribution network engineering in our country, and actively promote the standardization construction of distribution network engineering, is an international leader in research design of standardized distribution network engineering. All kinds of standard design of distribution network has been released nearly 60 of ${ }^{[3-7]}$, roughly covers the design of high voltage substation, low voltage distribution design of unattended substation Design of city underground substation design, overhead distribution line design, city power cable line cable tunnel design, design, design of low-voltage distribution network reconstruction, the preliminary design of electrical equipment safety design and distribution network engineering feasibility study, construction design content and so on. According to the provisions of the depth distribution network design content and the design process of comprehensive consideration. The distribution network design standards can be divided into substation circuit design standards, design standards, design standard design and evaluation criteria, the structure shown in Figure 1.

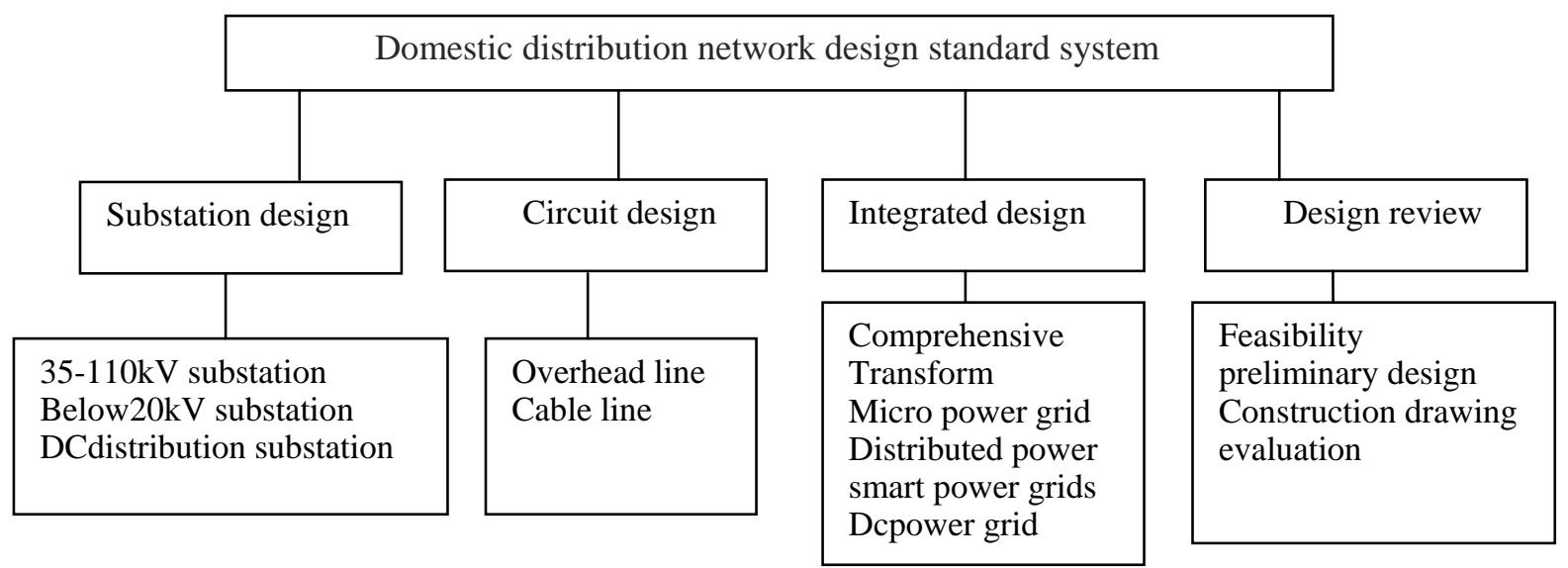

Figure 1 existing distribution network design standard system framework

\section{Problems in the design standard system of distribution network in China}

Generally speaking, there are some problems in the design standard system of distribution network:

(1) the standard system is not perfect, lack of systematic coordination. China's distribution network planning and design standard system is not complete, some of the new technology, the construction of distribution network of new materials, new equipment applications such as the lack of relevant standards, some standards do not conform to the actual situation of distribution network operation. The lack of top-level design of the system, system clearly, part of the standard size is too small, there are overlapping and even contradictory phenomenon between the standard, can not effectively guide the design of distribution network planning.

(2) the lack of standard management, implementation of the revised test results lack of formulation, planning and design standard of distribution network, implement and abolishment of 
work by the business department separate management, not mature management pattern formation; effect evaluation means lack of implementation of the standard, it is difficult to accurately track and feedback the standard application, re establishment, evaluation of light the problem.

(3) the new situation and new requirements under the background of reform of electric power system under the standard lack of adaptability, the incremental distribution business to unlock other relevant policy documents have been introduced, the construction of new urbanization, new energy development steadily, have adaptability to the planning and design standard of distribution network, pertinence and completeness put forward higher requirements.

From the substation design perspective, in the performance of specific issues: with the deterioration of the environment, energy supply, distributed energy is difficult to merge into AC grid problem is more prominent. And provides good conditions for grid connected DC power distribution network for distributed generation. The DC power distribution network in electric power development in the future has a broad application prospect, but the current lack of technical standard design of DC power distribution station, the need for the development of DC power distribution station design specification.

From the design perspective, in the performance of specific issues: the lack of technical standard of DC power distribution line design in our country, the need for design specification of DC power distribution lines, as part of the standard of new materials, new devices need to be revised.

From the point of view of integrated design, the specific problems in:

(1) the lack of design standard of active distribution network in our country, the active distribution network is to achieve large-scale intermittent operation of new energy grid control, power grid and charging facilities interaction, effective solutions of intelligent power grid operation and analysis of key technologies, the need to develop the active distribution network design specification, specifying a wiring mode active the distribution network of relay protection, distributed power access, data acquisition, communication system, distribution network automation, operation scheduling and design scheme implementation of.[4]

(2) the lack of design standard of DC power distribution network in China, distribution system with DC driven, in improving the operation efficiency of the distribution network, improve the power supply reliability and power quality, realize flexible distributed generation security access shows the superiority of the AC system do not have, need to design the DC power distribution network, used to the provisions of a DC connection mode of distribution network relay protection, distributed power access, data acquisition, communication system, distribution network automation, operation and implementation of the design scheme.

(3) the lack of standard for design of intelligent distribution network in China, need to design the intelligent distribution network, which provides monitoring, normal operation and accident intelligent distribution system under the situation of protection, control, management and distribution of electricity and intelligent.

From the design perspective, in the performance of specific issues: the lack of evaluation of the distribution automation system design guidelines and content depth provisions of the existing distribution network design and evaluation of China's standard, cannot regulate the distribution network design of the feasibility study, preliminary design, construction drawing design depth design.

\section{Research on Optimization of distribution network design standard system}

According to the actual situation of China's distribution network design, fully carding, analysis of domestic and national standards, industry standards, enterprise standards, work standards, specifications and documents on the basis of optimization, improve our existing distribution 
network planning and design standards, especially in the face of the new situation and new development of intelligent distribution network energy network. At present should be abolished, updated, added a series of standards and new, and put forward the distribution network standard system design optimization framework. Research ideas as shown in Figure 2.

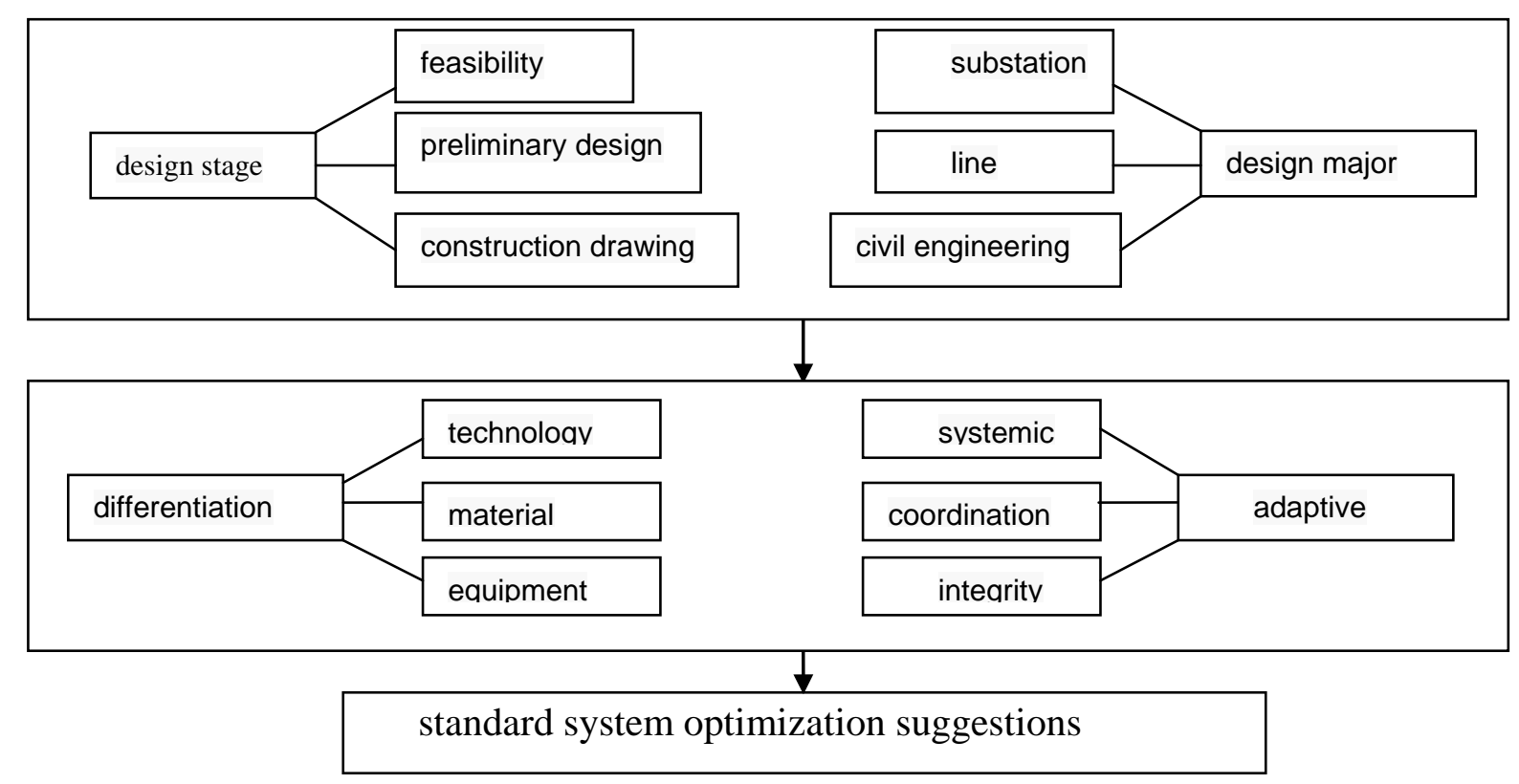

Figure 2 standard system optimization framework

\subsection{Optimization analysis}

In order to reverse the technical standard of heavy preparation, light adverse situation evaluation ", to strengthen the management of closed loop design standards, design standard system of distribution network mainly from the two aspects of integrated circuit design, design and carry out optimization design review work, focus on new materials, new equipment, new technology elements and distributed power, energy storage device and electric the car and other diversified load access conditions, not to revise the existing applicable standards, standards are lack of recommendations ${ }^{[8-9]}$.

\subsection{After the optimization of the standard system framework}

Sort out the existing distribution network standard system design from a professional point of view, can be divided into the power line design standards, design standards, design evaluation criteria and comprehensive design standards for four categories, as shown in Figure 3. At present, issued 15 national standards, industry standard 13, standard 29 enterprises, regulations the design principles and technical requirements of distribution network design should follow. Compared with figure 1, the new standard system has increased third levels in the hierarchy branch. 


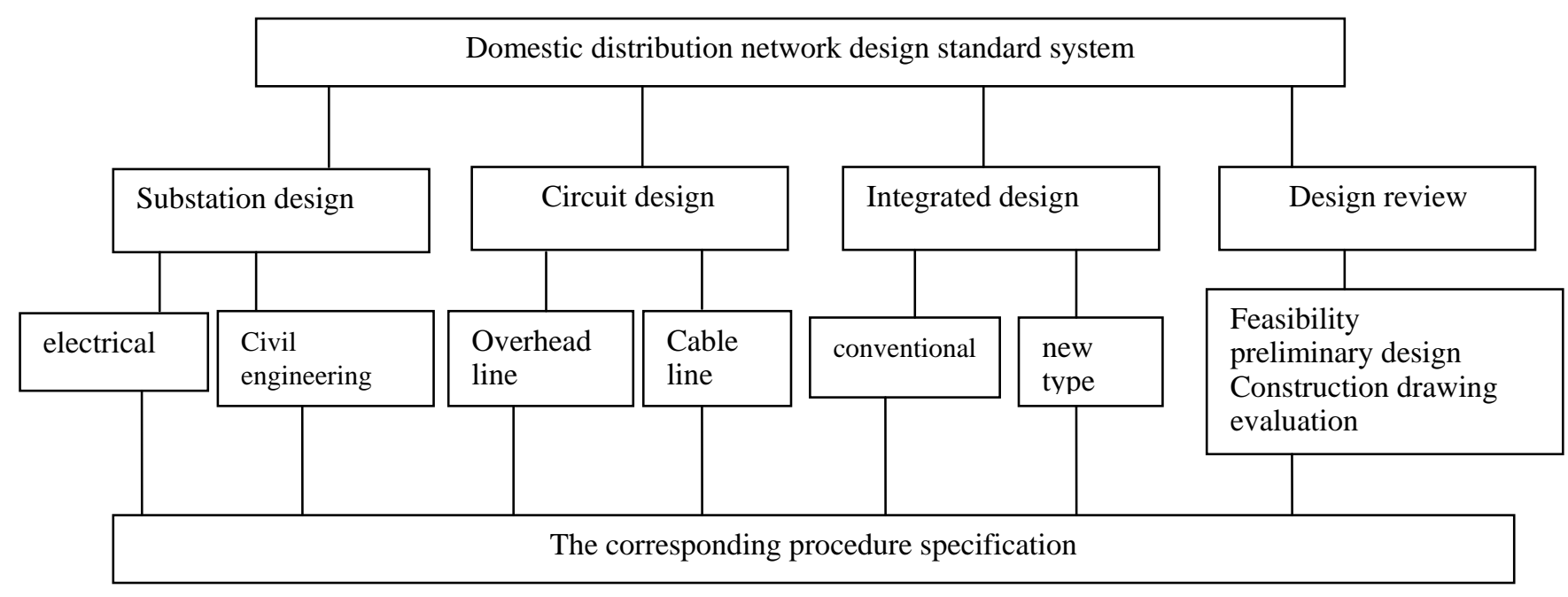

Fig. 3 standard system framework of distribution network design

\section{3 optimization measures}

According to the standard classification, from the design point of view, the proposed optimization criteria are as follows:

(1) line design standards:

The design content of cable tunnel excavation of cable tunnel excavation with suggestions < design guidelines $>$ and $<$ design guidelines $>$ Two standards involved in engineering design are similar, normative references can complement each other, combining with shield tunnel, pipe jacking tunnel into $<$ Specification for design of power cable $>$.

(2) comprehensive design standards:

Including the distributed generations design specifications, the electric vehicle charging facilities for electric power distribution network design specification, design specification for $10 \mathrm{kV}$ and below distribution network engineering, active distribution network design specification, design specification for intelligent distribution network, DC distribution network design in 6 aspects.

A. amendment to the distributed generations design specification. Suggestions: scope, normative references, terms and definitions, system time, distribution automation system two, distribution facilities, and the design scheme is selected.

B. develop the electric vehicle charging facilities design specification for access to distribution network. Proposals: general layout, charging equipment, power supply system, the two system construction, fire control.

C. specification design of $<10 \mathrm{kV}$ and below distribution network engineering. Suggestions: scope, normative references, terms and definitions, basic requirements, power supply area division and $10 \mathrm{kV}$ grid structure, power supply plan, distribution facilities, distribution facilities construction, project acceptance.

D. formulation of active distribution network design specification. Suggestions: scope, normative references, terms and definitions, principles, general requirements, power supply area division and planning objectives, load forecasting and power balance, the main technical principles, 35kV$110 \mathrm{kV}$ grid, $10 \mathrm{kV}$ distribution, 380/220V distribution network, the basic requirements of intelligent distribution network.

E. code for design of intelligent distribution network development. Suggestions: scope, normative references, terms and definitions, principles, general requirements, distribution of data communication network, measurement, protection and control technology, distribution automation, 
advanced measurement technology, DER network, the fault current limiting technology.

F. code for design of DC power distribution network development. Suggestions: scope, normative references, terms and definitions, principles, general requirements, power supply area division and planning objectives, load forecasting and power balance, the main technical principles, basic requirements of DC DC power distribution network, intelligent distribution.

(3) design review standards:

A. set < microgrid design guidelines for the assessment>. Suggestions: scope, normative references, terms and definitions, principles, general requirements, evaluation of the feasibility study, preliminary design, construction design and evaluation.

B. amendment to the National Engineering Power Grid Corp distribution network (preliminary drawings) Regulations on the design depth of content, with the new version of the typical design, fully consider the regional differences, and differences in factors such as climate and environment in urban and rural areas, to meet the requirements of new construction and renovation of national distribution network. Distribution network and standard of effective convergence, optimize equipment series, standard equipment technical parameters, unified the preliminary design and construction drawing design specifications and drawings content directory.

\section{Conclusion}

In this paper the design standard of the existing distribution network analysis, analysis of the existing standard system adaptability, existing distribution network design in accordance with the standards of four professionals, four levels of classification, considering key distribution design and construction under the new situation, mainly from the overall design and design review of two professional gives some optimization suggestions. The distribution network design standards to further improve the system, to provide strong support for the distribution network engineering to achieve closed-loop management.

\section{References}

[1] DC distribution network research status and prospects [J] .Jiangdao Zhuo, Zheng Huan. Power System Automation. 2012 (08).

[2] Active distribution network technology and its progress [J] .You Yi, Liu Dong, Yu Wenpeng, Chen Fei, Pan Fei. Power System Automation. 2012 (18).

[3] Urban low-voltage distribution network transformation technology guide $<$ DL / T599-2016> [S].

[4] distributed power access grid technical requirements $<$ Q / GDW 1480-2015 $>$ [S].

[5] 10kV and below the overhead distribution line design technical regulations $<\mathrm{DL} / \mathrm{T}$ 5220-2005 $>$ [S].

[6] distributed power access system design content depth<Q / GDW 11148-2013 $>$ [S].

[7] 20kV and below substation design specifications $<$ GB 50053-2013 $>$ [S].

[8] Random coordination of electric vehicle and renewable energy in power distribution system [J]. Wang Guibin, Zhao Junhua, Wen Futuo, Xue Yusheng, Xin Jianbo. Power System Automation. 2012 (19).

[9] active power distribution system feasible technology research [J]. Fan Mingtian, Zhang Zuping, Su Aixue, Su Jian. China Journal of Electrical Engineering. 2013 (22). 